http://dx.doi.org/10.23925/1983-3156.2021v23i2p130-159

\title{
Percepções de licenciandos/as em matemática sobre avaliação da aprendizagem
}

Mathematics undergraduate students' perceptions about the assessment practices

Percepciones de los estudiantes de matemáticas de pregrado sobre la evaluación del aprendizaje

\author{
Niusarte Virgínia Pinheiro ${ }^{1}$ \\ Universidade Federal do Vale do Jequitinhonha e Mucuri \\ https://orcid.org/0000-0001-5172-0719 \\ Samira Zaidan ${ }^{2}$ \\ Universidade Federal de Minas Gerais \\ https://orcid.org/0000-0001-7163-5546
}

\begin{abstract}
Resumo
Este estudo objetiva analisar percepções de licenciandos/as sobre as práticas avaliativas em um curso de licenciatura em matemática e discutir implicações para a aprendizagem dos conteúdos específicos matemáticos. Trata-se de resultado de uma pesquisa qualitativa, expositiva e explicativa. O curso e os/as estudantes foram selecionados/as por amostra não probabilística acidental. Os dados foram produzidos mediante as seguintes ações metodológicas: análise documental, observação de aulas, entrevista semiestruturada, a promoção de uma roda de conversa, acesso a redes sociais - grupos fechados: Facebook e WhatsApp, procedendo-se à análise do conteúdo. As bases teóricas de análise foram a teoria da reprodução e uma concepção de avaliação da aprendizagem como processo formativo integrado à prática docente. Nossos/as interlocutores/as manifestaram acentuada preocupação com a obtenção de notas para aprovação e advogaram a favor da prova tradicional como o instrumento adequado e fidedigno para aferir a aprendizagem. Na percepção da maior parte deles/as, diversificar instrumentos de avaliação, além da prova, significa facilitar a aprovação, rebaixar o nível de exigência e a qualidade do curso. Outra parte deles/as mostra grande dificuldade com a avaliação praticada
\end{abstract}

\footnotetext{
${ }^{1}$ niusarte@gmail.com

2 samira@fae.ufmg.br
} 
no curso, compreendendo-a como seletiva e indicando a necessidade de diversificação dos instrumentos avaliativos. Há um silenciamento dos/as interlocutores/as em relação à concepção de avaliação formativa e integrada à prática pedagógica. Expressam uma percepção inicial e nebulosa do caráter oculto e legitimador da avaliação que, ao classificá-los/as e selecionálos/as, responsabiliza-o/as por seus êxitos e fracassos.

Palavras-chave: Avaliação da aprendizagem, Formação docente, Violência simbólica, Educação matemática.

\begin{abstract}
This study aims to analyse undergraduate students' perceptions of the assessment practices in a mathematics teaching degree course and discuss implications for the learning of specific mathematical contents. It is the result of a qualitative, expository, and explanatory research. The course and students were selected by an accidental non-probabilistic sample. The data were produced through the following methodological actions: document analysis, classroom observation, semi-structured interview, conversation circle, and access to social networks closed groups Facebook and WhatsApp, proceeding to content analysis. The theoretical bases of analysis were the theory of reproduction and a conception of assessment of learning as a formative process integrated to the teaching practice. Our interlocutors expressed a strong concern with obtaining grades for approval and advocated for the traditional test as the proper and reliable instrument for measuring learning. For most participants, diversifying assessment instruments, in addition to the test, means facilitating approval, thus lowering the level of demand and quality of the course. Others find the course assessment difficult, understanding it as selective and indicating the need for diversification of the assessment instruments. The interlocutors keep silent regarding the concept of formative assessment integrated with pedagogical practice. They express an initial and nebulous perception of the hidden and
\end{abstract}


legitimising character of the assessment which, by classifying and selecting them, makes them responsible for their successes and failures.

Keywords: Learning assessment, Teacher education, Symbolic violence, Mathematics education.

\section{Resumen}

Este estudio tiene como objetivo analizar las percepciones sobre las prácticas de evaluación de los estudiantes de un curso de pregrado en matemáticas y discutir las implicaciones para el aprendizaje de contenidos matemáticos específicos. Presentamos estos elementos como resultado de una investigación cualitativa, expositiva y explicativa. El curso y los estudiantes fueron seleccionados mediante una muestra accidental no probabilística. Los datos se produjeron a través de las siguientes acciones metodológicas: análisis de documentos, observación de clases, entrevista semiestructurada, promoción de un círculo de conversación, acceso a redes sociales - grupos cerrados de Facebook y WhatsApp- y, finalmente, el desarrollo de los análisis de contenido. Las bases teóricas del análisis fueron la teoría de la reproducción y una concepción de la evaluación del aprendizaje como un proceso formativo integrado con la práctica docente. Nuestros interlocutores expresaron una gran preocupación por obtener calificaciones para la aprobación y abogaron por la prueba tradicional como el instrumento apropiado y confiable para evaluar el aprendizaje. En la percepción de la mayoría de ellos, diversificar los instrumentos de evaluación, además de la prueba, significa facilitar la aprobación, rebajando el nivel de exigencia y la calidad del curso. Una parte del grupo de estudiantes mostró una gran dificultad con la evaluación practicada em el curso, entendiéndola como selectiva e indicando la necesidad de diversificación de los instrumentos de evaluación. Hay un silencio de los interlocutores con relación al concepto de evaluación formativa e integrada con la práctica pedagógica. Expresan una percepción inicial y nebulosa del carácter 
oculto y legitimador de la evaluación que, al clasificarlos y seleccionarlos, los responsabiliza de sus aciertos y fracasos.

Palabras clave: Evaluación del aprendizaje, Formación de profesores, Violencia simbólica, Educación matemática.

\section{Résumé}

L'objectif de cette étude est d'analyser les perceptions sur les pratiques d'évaluation des étudiants d'un cours de Premier Cycle en Mathématiques et de discuter les implications pour l'apprentissage de contenus mathématiques spécifiques. Nous présentons ces éléments comme résultat d'une recherche qualitative, expositoire et explicative. Le cours et les étudiants ont été sélectionnés à l'aide d'un échantillon accidentel non probabiliste. Les données ont été produites selon les actions méthodologiques suivantes : analyse de documents, observation de classes, entretien semi-structuré, promotion d'un cercle de conversation, accès aux réseaux sociaux groupes fermés de Facebook et WhatsApp - et, finalement, développement de l'analyse de contenu. Les bases théoriques de l'analyse étaient la théorie de la reproduction et une conception de l'évaluation de l'apprentissage comme processus de formation intégré à la pratique pédagogique. Nos interlocuteurs ont exprimé une grande inquiétude quant à l'obtention de notes de passage et ont préconisé le test traditionnel comme instrument approprié et fiable pour évaluer l'apprentissage. Dans la perception de la plupart d'entre eux, diversifier les instruments d'évaluation, en plus du test, signifie faciliter la réussite, abaissant le niveau de demande et la qualité du cours. Une partie du groupe d'étudiants a montré une grande difficulté avec l'évaluation faite pendant le cours, l’ont considérée comme sélective et ont indiqué la nécessité d'une diversification des instruments d'évaluation. Il y a un silence de la part des interlocuteurs par rapport au concept d'évaluation formative et intégrée avec la pratique 
pédagogique. Ils expriment une perception initiale et nébuleuse du caractère caché et légitimateur de l'évaluation qui, en les classant et en les sélectionnant, les rend responsables de leurs succès et leurs échecs.

Mots-clés : Évaluation des apprentissages, Formation des enseignants, Violence symbolique, Enseignement des mathématiques. 


\section{Percepções de licenciandos/as em Matemática sobre avaliação da aprendizagem}

Os índices de reprovação e evasão nas disciplinas de conteúdo específico matemático nos cursos de licenciatura em Matemática, não raro, são elevados no Brasil, conforme indicadores educacionais no portal do Instituto Nacional de Estudos e Pesquisas Educacionais Anísio Teixeira (Inep, 2020). Muitos questionamentos surgem diante disso e, então, buscamos compreender fatores que contribuem para a existência e a persistência desse fenômeno, assim como as implicações para a formação docente que podem ser apontadas baseadas na vivência da avaliação para a aprendizagem dos conteúdos matemáticos.

Nossa pesquisa ${ }^{3}$ buscou analisar a avaliação da aprendizagem nas disciplinas de matemática em um curso de licenciatura porque, para um curso disciplinar, o ensino específico pode ser apontado como central na formação proposta. Optamos por compreender as percepções dos/as licenciandos/as em uma experiência de curso. Perguntamos: como os/as licenciandos/as percebem as práticas avaliativas no curso de Licenciatura em Matemática, quais as implicações dessas práticas para suas aprendizagens e, por desdobramento, para sua visão de avaliação como futuros/as professores/as?

Cabe ressaltar que, neste trabalho, advogamos a favor da concepção de avaliação com função formativa - como um elemento integrado à prática pedagógica. Nessa direção, Buriasco e Soares (2008) defendem que a avaliação deve ser concebida como um processo de investigação, compartilhado por docentes e discentes, de caráter sistêmico e dinâmico. Para as autoras, "as tarefas de aprendizagem devem se constituir, ao mesmo tempo, em tarefas de avaliação, uma vez que a avaliação é parte integrante da rotina das atividades escolares e não uma sua lacuna” (p. 110).

\footnotetext{
${ }^{3}$ Pesquisa apoiada pelo Conselho Nacional de Desenvolvimento Científico e Ttecnológico (CNPq).
} 
Como D’Ambrosio (2007), entendemos que entre os maiores entraves para a melhoria da educação e, para a educação matemática, em particular, estão os elevados índices de estudantes que são reprovados/as e/ou abandonam a escola, em todos os níveis do sistema educacional. Há um conjunto de fatores que podem contribuir para isso, mas reconhecemos na avaliação um deles. $\mathrm{O}$ autor critica a abordagem tradicional de avaliação praticada por meio de provas e exames, com vistas à classificação e à seleção dos estudantes: “o fato é que as provas convencionais pouco dizem sobre o que o aluno sabe" e que, "na verdade, os alunos passam por testes para os quais são treinados. É essencial distinguir educação de treinamento" (D’Ambrosio, 2007, p. 76-77).

Além dos estudiosos da temática avaliação da aprendizagem, para alcançar o objetivo proposto, filiamo-nos à teoria de Bourdieu e Passeron (1982), particularmente, aos estudos sobre a reprodução das desigualdades sociais no contexto escolar e a centralidade da avaliação como um instrumento que as legitima na prática pedagógica.

Na obra A Reprodução: elementos para uma teoria do sistema de ensino, Bourdieu e Passeron (1982) desenvolveram a teoria da reprodução por meio do conceito de violência simbólica ao analisar o sistema escolar francês. Nesse livro, os autores abordam o peso, as características e as funções dos exames em um sistema de ensino, e afirmam que "é demasiado evidente que o exame domina a vida universitária, isto é, não apenas as representações e as práticas dos agentes, mas também a organização e o funcionamento da instituição" (Bourdieu \& Passeron, 1982, p. 153). Para os sociólogos,

[...] o exame não é somente a expressão mais legível dos valores e das escolhas implícitas do sistema de ensino, ele "impõe uma definição social do conhecimento e da maneira de manifestá-lo, oferece um de seus instrumentos mais eficazes ao empreendimento de inculcação da cultura dominante e do valor dessa cultura (Bourdieu \& Passeron, 1982, p. 153).

Os autores observam que "a maioria daqueles que, em diferentes fases do curso escolar, são excluídos dos estudos se eliminam antes mesmo de serem examinados e que a proporção 
daqueles cuja eliminação é mascarada pela seleção abertamente operada difere segundo as classes sociais" (Bourdieu \& Passeron,1982, p. 163). Nesse processo de eliminação, o exame é um instrumento estratégico de legitimação da exclusão das camadas populares do sistema escolar.

Nada é mais adequado que o exame para inspirar a todos o reconhecimento da legitimidade dos veredictos escolares e das hierarquias sociais que ele legitima, já que ele conduz aquele que é eliminado a se identificar com aqueles que malogram, permitindo aos que são eleitos entre um pequeno número de elegíveis ver em sua eleição a comprovação de um mérito ou de um “dom" [...] (Bourdieu \& Passeron, 1982, p. 171).

Nogueira e Nogueira (2016, p. 83) destacam a relevância dos pressupostos teóricos de

Bourdieu e, em particular, da avaliação da aprendizagem escolar:

[...] no que concerne ao tema da avaliação escolar, o trabalho científico de Bourdieu deixou um legado crítico importante, principalmente porque desvelou a função social da avaliação (de classificação social e hierarquização dos indivíduos) que se disfarça sob as aparências de sua função técnica (classificação escolar dos alunos).

A avaliação nesses termos é um processo que, de forma implícita e mascarada, exerce o controle do conhecimento e dissimula o controle das hierarquias sociais, "na medida em que define o que deve saber o estudante e avalia se ele sabe tudo o que deve saber e apenas o que deve saber, e ainda se sabe tal como deve saber" (Soares, 1989, p. 48).

A Matemática, quando concebida sob a perspectiva formalista clássica (Fiorentini, 2005) ou, nos termos de D’Ambrosio (1993, p.35), em uma visão absolutista, “com resultados precisos e procedimentos infalíveis, cujos elementos fundamentais são as operações aritméticas, procedimentos algébricos e definições e teoremas geométricos”, é considerada por muitos como uma área de conhecimento complexa e difícil. Um campo cujo reconhecimento da legitimidade dos veredictos acadêmicos, por meio dos exames ou das tradicionais provas, impõe-se com força.

Os/As estudantes que apresentam êxito na Matemática, nessa perspectiva, frequentemente, aparecem associados à inteligência, ao talento nato, aos méritos individuais e, 
de acordo com Bourdieu e Passeron (1982), trata-se da ideologia do dom. Para Jourdain e Naulin (2017, p. 71), essa ideologia "postula que as diferenças de sucesso escolares são inteiramente atribuídas às aptidões ou aos méritos individuais" e permitem legitimar a posição social dos estudantes. Os autores referem-se às desigualdades ante a cultura da elite, predominante nos processos de escolarização, e demonstram que estas se perpetuam por meio dos processos pedagógicos e, particularmente avaliativos, transformando privilégios sociais em talentos individuais, méritos ou dons, legitimando-os. Nesse sentido, Bourdieu (2015, p. 241) afirma:

[...] o sistema de ensino tende a transformar os privilégios sociais em privilégios naturais, e não de nascimento: a "inteligência", o "talento" ou o "dom" são os títulos de nobreza da sociedade burguesa que a escola consagra e legitima ao dissimular o fato de que as hierarquias escolares que ela produz por uma ação de inculcação e de seleção aparentemente neutra, reproduzem as hierarquias sociais no duplo sentido do termo.

Bourdieu e Passeron (2015, p. 39) explicam que "todo ensino e mais particularmente o ensino de cultura (mesmo científica), pressupõe implicitamente um corpo de saberes, de saberfazer e, sobretudo, de saber-dizer, que constitui o patrimônio das classes cultas". Destacam que "para os filhos de camponeses, de operários, de empregados ou de pequenos comerciantes, a aquisição da cultura escolar é aculturação" (Bourdieu \& Passeron, 2015, p. 40), sendo aculturação "a aprendizagem da cultura da elite é uma conquista, pela qual se paga caro" (p. 42).

O custo da aculturação, no caso da aprendizagem dos conteúdos matemáticos, é elevado porque, frequentemente, estes são ministrados de forma tradicional, como afirma Fischer (2008):

Ainda é comum encontrar, entre professores de matemática, principalmente no ensino superior, apenas formatos tradicionais de conduzir uma aula. É aquela sequência do tipo: exposição da matéria no quadro, apresentação de algum exemplo e, em seguida, uma lista de exercícios para os alunos (Fischer, 2008, p. 77).

A prática pedagógica e, nesta, a avaliação da aprendizagem na concepção tradicional, exige dos aprendizes um esforço e uma dedicação muito grandes e pode ser um dos fatores 
dificultadores da aprendizagem dos sujeitos oriundos das classes populares, pois, no dizer de Bourdieu e Passeron (1982, p. 36), "reduzir a relação de comunicação pedagógica a uma pura e simples relação de comunicação é abster-se de compreender as condições sociais de sua eficácia propriamente simbólica e propriamente pedagógica $[\ldots]$..."

\section{Em busca dos dados para compreensão do problema}

Recorremos à metodologia qualitativa de pesquisa de campo de inspiração etnográfica, descritiva e explicativa, buscando apreender os acontecimentos e relações sociais na prática pedagógica das disciplinas de conteúdo específico, com base na perspectiva dos/as licenciandos/as. Isso, porque serão eles/as os sujeitos protagonistas do processo de formação que, além de vivenciarem os desafios no processo de aprendizagem, irão construir suas formas próprias de pensar e agir na futura profissão.

O campo de estudo foi um curso de Licenciatura em Matemática de uma Instituição Federal de Ensino Superior (Ifes), no qual são ofertadas as modalidades bacharelado e licenciatura. A Ifes é de grande porte e de tradição no país, sendo que a unidade que coordena o curso possui um campo estabelecido na pesquisa em Matemática. A Ifes, o curso e os/as estudantes foram selecionado/as por amostra não probabilística acidental. Cabe esclarecer que os/as estudantes e docentes - envolvidos/as com as disciplinas consideradas na pesquisa autorizaram sua participação, segundo as normas da ética na pesquisa.

Todos os/as estudantes matriculados/as nas disciplinas de conteúdo específico matemático a partir do quarto período foram convidados/as para participar da pesquisa. Ao todo, 67 atenderam aos critérios preestabelecidos e desses, 42 participaram: 12 entrevistados/as; 16 participaram da roda de conversa e, entre estes, quatro estão entre os entrevistados/as; 18 participaram apenas por meio das redes sociais WhatsApp e/ou Facebook.

Sobre o perfil socioeconômico dos/as licenciandos/as, foram considerados como sujeitos pertencentes, em sua maioria, às camadas populares, em conformidade com os 
resultados das amplas pesquisas realizadas por Moreira et al. (2012) e Gatti; Barreto (2009), referentes aos/às estudantes de Licenciatura em Matemática no Brasil.

Para fins deste estudo, as técnicas utilizadas foram a análise documental (Projeto Pedagógico do Curso - PPC - e programas das disciplinas), observações de aulas, entrevistas semiestruturadas com estudantes, roda de conversa e, ainda, dados de redes sociais dos próprios licenciando/as - Facebook e WhatsApp.

A análise do PPC e dos programas das disciplinas de matemática nos ofereceram informações gerais sobre a proposta de avaliação da aprendizagem. Indicam os estudos de Silva (2014), ao analisar 26 organizações curriculares de cursos de instituições públicas brasileiras, que esses documentos não contemplam com consistência a temática avaliação da aprendizagem: “a formação nas Licenciaturas em Matemática não engloba, de forma aprofundada, as experiências práticas concretas e as discussões teóricas correntes relacionadas com a avaliação da aprendizagem escolar" (Silva, 2014, p.72).

Realizamos uma observação das disciplinas obrigatórias para a licenciatura durante todos os dois semestres do ano 2017: Fundamentos de Geometria Plana e Desenho Geométrico, Geometria Espacial, Variável Complexa e Fundamentos de Análise, no quarto, quinto, sexto e sétimo semestres do curso, respectivamente. Isso porque os alunos podem optar pela licenciatura a partir do quarto período, logo nosso contato ocorreu com todos os licenciandos do curso. Na Ifes, o sistema de matrícula é por disciplina e estudantes de bacharelado podem matricular-se em disciplinas da licenciatura e vice-versa, mas nas obrigatórias estão matriculados/as, majoritariamente, licenciandos/as.

Promovemos um encontro dos/as estudantes, que denominamos por Roda de Conversa pelo seu caráter de participação livre e espontânea, no qual contamos com presença de 16 licenciandos/as, em que "a identidade do pesquisador e os objetivos do estudo são revelados ao grupo pesquisado desde o início" (Ludke \& André, 1986, p.29). A Roda de Conversa teve 
duração de 1h50min. Por meio dessa técnica, promovemos uma reflexão sobre como os/as estudantes pensam, sentem e agem a respeito da avaliação praticada no curso, sendo conduzida na perspectiva teórica de Paulo Freire, como "um método ativo, dialogal, participante [...]". (Freire, 2005, p. 115).

As observações foram registradas em um diário de campo, no qual descrevemos as informações referentes às aulas, às conversas informais com os/as discentes antes e depois das aulas, nos corredores, na cantina, bem como as análises do que foi ouvido, visto e percebido durante a imersão no campo.

A primeira autora desse estudo, inserida no grupo Facebook, composto por estudantes do Departamento de Matemática e nos grupos WhatsApp das disciplinas, ambos criados para divulgar e discutir questões relacionadas às aulas e docentes, passou a ter acesso à socialização de informações diversas e, especialmente, diálogos sobre a prática docente, a avaliação da aprendizagem, reclamações, entre outras questões.

Não incluímos os/as professores/as como interlocutores/as nessa investigação, com eles/as conversamos e expusemos os objetivos da pesquisa, acreditando que suas propostas se expressavam nos planos de cursos e na condução cotidiana das atividades didáticas e, principalmente, porque nosso foco se coloca nas percepções dos/as licenciandos/as.

Buscamos as percepções dos/as licenciandos/as por meio de reflexões com base nas suas experiências no curso. Trabalhamos com o conceito de percepção na perspectiva de Polettini (1996), para quem é de grande importância a reflexão em torno das experiências durante a formação docente. Percepções como indicações (introspecções) que os sujeitos têm e expressam atualmente, resultado de um processo de reflexão sobre suas experiências presentes e passadas.

Com esse olhar, submetemos os dados à análise de conteúdo (Bardin, 2016) pela qual definimos, a priori, o tema como unidade de registro, e classificamos as falas dos/as 
interlocutores/as nas categorias: concepção de avaliação e implicações da avaliação para a aprendizagem dos conteúdos específicos matemáticos.

De acordo com Bardin (2016, p. 135), “o tema é geralmente utilizado como unidade de registro para estudar motivações de opiniões, de atitudes, de valores, de crenças, de tendências etc." A autora aponta que "fazer uma análise temática consiste em descobrir os "núcleos de sentido' que compõem a comunicação e cuja presença, ou frequência de aparição, podem significar alguma coisa para o objetivo analítico escolhido" (Bardin, 2016, p. 135).

Identificadas as unidades de registros, estabelecemos as unidades de contexto, buscando, sobretudo, compreender as indicações efetuadas pelos/as licenciandos/as, identificando o sentido e o significado das mensagens (percepções) alocadas nos eixos temáticos que emergiram do corpus de dados que serão analisados a seguir.

\section{Percepções dos/as licenciandos/as acerca das concepções e implicações da avaliação para a aprendizagem}

Para analisar as percepções dos/as licenciandos/as, identificamos quatro eixos temáticos, abordados a seguir: a frequência às aulas, a concepção de matemática e de como se aprende matemática, a formação dos/as docentes formadores/as e rendimentos dos/as docentes nas disciplinas de matemática. Demos, aos/às licenciandos/as, nomes de pedras preciosas ${ }^{4}$ e alguns depoimentos serão aqui citados.

\section{Da frequência versus não frequência às aulas}

Das sete disciplinas observadas, notamos que os/as docentes não controlaram a frequência dos/as alunos/as com regularidade, alguns verificando presença nos primeiros dias de aula, e todos sempre nos dias de prova. Diante dessa constatação, questionamos: qual a importância desse fato para a aprendizagem dos/as alunos/as?

\footnotetext{
4 Os nomes usados aqui são: Citrino, Esmeralda, Esfênio, Ametista, Rubelita, Jasper, Coralina, Hematita, Euclásio, Rodolita, Sodolita e Ágata.
} 
Segundo o estudante Citrino, é normal não assistir às aulas: “criou-se uma cultura aqui dentro da IFES de que é tudo bem, é não frequentar as aulas. Então o aluno que chega, ele entra nessa cultura, então se o professor não cobrar chamada, o aluno não vai na aula e, aí, ele tem obrigação de aprender sozinho".

Essa situação pode ser observada no questionamento da estudante Esmeralda, dirigido aos seus colegas, via WhatsApp: "Alguem (sic) sabe que horas o [docente] costuma fazer chamada? Pois estou assistindo mais vídeo aulas no YouTube sobre essa matéria, já que na aula dele eu fico boiando (risos)".

Não assistir à aula é uma realidade também apontada pelo licenciando Esfênio ao relatar que, em algumas matérias, só vai fazer prova: "Variável Complexa, por exemplo, que eu fiz, teve quatro provas, eu fui em cinco aulas. Quatro aulas que era prova e uma aula só para conhecer o professor. Passei com $65[\ldots] "$ ".

A aluna Ametista explica que no semestre em curso está matriculada em oito disciplinas, não frequenta todas as aulas e consegue obter bons resultados: "Fundamentos de Análise estou indo bem, não vou na aula. Das aulas todas, disso tudo que eu estou fazendo, o que eu vou é estágio [...] e Geometria na Educação Básica. Ah! A outra é História da Matemática, são as únicas”. A fala da aluna, a seguir, indica que sua prioridade é alcançar nota para aprovação:

Ametista: Esse semestre eu estou fazendo oito matérias...

Pesquisadora: E você está dando conta de todas?

Ametista: Não.

Pesquisadora: E o que você pretende fazer?

Ametista: Eu quero passar (risos).

Esmeralda afirma que muitos/as docentes defendem que os/as alunos/as sejam autodidatas: "Então muitos já chegaram a falar, olha, vocês têm que estudar é sozinho mesmo, 
porque eu não posso fazer muita coisa por vocês, aqui tem que ser autodidata mesmo, vocês têm que ler o livro e fazer os exercícios".

A autodidaxia é uma ideia difundida entre os/as docentes e discentes. Sobre a capacidade de aprender sem a mediação do professor, Bourdieu (2017) afirma:

[...] não será um paradoxo considerar a relação autodidata com a cultura e o próprio autodidata como produtos do sistema escolar, aliás, o único habilitado não só a transmitir este corpo hierarquizado de aptidões e saberes que constitui a cultura legítima, mas também a consagrar, pelo exame e pelos diplomas, o acesso a determinado tipo de iniciação. Por ter adquirido sua cultura fora da ordem legítima instaurada pela instituição escolar, o autodidata está destinado a denunciar incessantemente, em sua própria ansiedade relativa à boa classificação, a arbitrariedade de suas classificações e, por conseguinte, de seus saberes, espécie de pérolas sem fío acumuladas no decorrer da aprendizagem singular, ignorando as etapas e os obstáculos institucionalizados e padronizados, os programas e progressões que transformam a cultura escolar em um conjunto hierarquizado e hierarquizante de saberes imprescindíveis (Bourdieu, 2017, p. 307).

Como produto do sistema escolar, a autodidaxia é considerada como um fator de hierarquização das disciplinas escolares, de classificação dos/as estudantes, legitimação da cultura privilegiada no sistema escolar e da meritocracia. Os sujeitos adquirem e acumulam a cultura, nesse caso, os conteúdos matemáticos, em procedimento informal legitimado pela prática na instituição, ou seja, tornam-se autodidatas e porta-vozes dos saberes acumulados. Em outras palavras, destacam-se, adquirem o status de "bom aluno" e recebem o reconhecimento acadêmico. Questionado sobre ser autodidata, Citrino responde:

Pesquisadora: Você aprende mais na sala ou estudando sozinho?

Citrino: Na sala, com certeza, mas eu entendo, eu vejo isso mais como uma característica minha mesmo, em geral, os estudantes de universidade aprendem mais estudando sozinhos.

Ao utilizar a expressão "uma característica minha, mesmo", o licenciando Citrino pode comprovar o que Bourdieu denomina de "efeito de legitimação provocado pela ocultação das bases sociais do sucesso escolar", conforme explicam Nogueira e Nogueira (2016, p. 75). De 
acordo com os autores, esse efeito é duplo e manifesta-se nos/as estudantes das camadas dominantes e dominadas. Nos dominantes,

[...] pelo fato de terem recebido sua herança cultural desde muito cedo e de modo difuso, desapercebido, insensível teriam dificuldade de se reconhecerem com "herdeiros". Suas disposições e aptidões culturais e linguísticas lhes pareceriam naturais ou, em outros termos, componentes - até certo ponto inatos - de sua personalidade (Nogueira \& Nogueira, 2016, p. 75).

Nos dominados, "sendo incapazes de perceber o caráter arbitrário e impositivo da cultura escolar, tenderia a atribuir suas dificuldades escolares a uma inferioridade que lhes seria inerente definida em termos intelectuais (falta de inteligência) ou morais (fraqueza de vontade)" (Nogueira \& Nogueira, 2016, p. 75).

O comentário da estudante Rubelita, a seguir, revela possibilidade de incorporação, em termos intelectuais, do efeito arbitrário e impositivo da cultura escolar. Podemos entender que a cultura dominante, nesse caso, trata-se da concepção clássica de matemática, que Bourdieu denomina de arbitrário cultural:

Mas quando é a Matemática pura, qualquer coisa, se você me mandar fazer qualquer continha boba, eu tenho um pouco de, é um pouco devagar, meu raciocínio, é um pouco mais devagar. [...] Mas eu acho que a gente fica naquela coisa, a gente está tão acostumado aqui no Departamento de Matemática a ir tão mal, mas esse é mal nosso, claro!

Ametista indica provável internalização do efeito arbitrário e impositivo da cultura escolar em termos morais, ou seja, relacionando-o à fraqueza de vontade: "Eu falo que eu dou muita sorte, eu acho, porque eu sou muito picareta, sou exemplo de aluno picareta, eu passo na picaretagem, muitas vezes. [...] Eu estudo na véspera de prova, entendeu?"

Apesar de uma possível incorporação dos efeitos de legitimação da cultura dominante, expressos nesses comentários, há fortes críticas quanto ao formato de aula expositiva praticada no curso. Jaspe afirma que assistir ou não às aulas não faz diferença para obter aprovação: "Então, às vezes, nem depende da aula, às vezes, depende de você sentar a bunda na cadeira e estudar a matéria que você sabe que vai precisar". 
Os/As estudantes mencionaram, ainda, que podem recorrer ao atendimento individual ou coletivo nos gabinetes dos/as docentes para dirimir dúvidas, especialmente durante a resolução das listas de exercícios. A prática de esclarecer dúvidas nos gabinetes dos professores que se colocam à disposição é adotada como uma estratégia utilizada pelos/as estudantes em geral, como explica Esmeralda: “[...] quando tenho dúvidas, quando faço exercício, vou lá na sala do professor". Contudo, a maior parte dos/as estudantes diz que nem sempre consegue utilizar essa prerrogativa, como Coralina: "Não, não, nem sempre, por falta de tempo, não porque não gostasse [...]. É por trabalhar e estudar não sobrava muito tempo”.

Não assistir às aulas, estudar por 'conta própria', procurar os/as professores/as nos gabinetes para esclarecer dúvidas, em especial nas vésperas das provas, e fazer as provas parecem ser procedimentos rotineiros, naturalizados, nas disciplinas de conteúdo específico. Alguns/as professores/as, por sua vez, não controlam a frequência, facultando, indiretamente, a presença do/a aluno/a em sala de aula, fato indicativo de que os/as alunos/as precisam se tornar autodidatas. É possível inferir que a maior parte deles/as não vê razão para frequentar as aulas, já que pelos livros ou apostilas terão acesso ao conhecimento que o/a professor/a apresentará e também, segundo a expressão de alguns/as, porque não conseguem acompanhar e compreender os conteúdos ministrados por meio de aulas expositivas.

A visão e prática em que os/as futuros/as professores/as estão imersos/as, sugerem uma concepção formalista clássica de Matemática (Fiorentini, 2005) ou absolutista que "se caracteriza pela lógica formal e pelo predomínio da razão absoluta, a noção de matemática como uma coleção de verdades a serem absorvidas pelos alunos, uma disciplina cumulativa, predeterminada e incontestável [...]"' (D’Ambrosio, 1993, p. 35).

Nesse contexto, interessa-nos compreender: qual visão de Matemática os/as licenciandos/as demonstram ter? Como eles/as percebem o processo de ensino e aprendizagem das disciplinas de conteúdo específico? 


\section{Da concepção de Matemática e de como se aprende matemática}

$\mathrm{Na}$ abordagem observada no curso analisado, o ensino da Matemática consiste na transmissão de conhecimentos, o que dificulta enxergar a matemática como um campo de pesquisa historicamente construído, confluindo na proposição de resolução de grandes quantidades de exercícios repetitivos. Por essa ótica, no entendimento de muitos/as docentes, “o aluno aprenderá melhor quanto maior for o número de exercícios por ele resolvido. Será que de fato essa resolução de exercícios repetitivos de certos algoritmos e esquemas de solução geram o aprendizado?” (D’Ambrosio, 1993, p. 36).

Ao questionar se a prática de resolução de grande quantidade de exercícios de fato contribui para gerar aprendizagem, D’Ambrosio (1989, p. 1) destaca consequências, os “alunos passam a acreditar que a aprendizagem de matemática se dá por meio de um acúmulo de fórmulas e algoritmos. Aliás, nossos alunos hoje acreditam que fazer matemática é seguir e aplicar regras. Regras essas que foram transmitidas pelo professor". Uma metodologia que expressa uma visão de Matemática.

Os alunos acham que a matemática é um corpo de conceitos verdadeiros e estáticos, do qual não se dúvida ou questiona, nem mesmo nos preocupamos em compreender por que funciona. Em geral, acreditam também, que esses conceitos foram descobertos ou criados por gênios (D’Ambrosio, 1989, p.1).

Pelo exposto, consideramos relevante interrogar: quais são as percepções dos/as futuros/as professores/as sobre como se aprende matemática? Há um entendimento predominante de que se aprende matemática resolvendo uma grande quantidade de exercícios, ou seja, aprende-se matemática para aplicar em resoluções de exercícios o que, para além da capacidade operatória, proporciona uma assimilação do que é e como funciona a matemática. De acordo com Fiorentini $(1995$, p. 7), “[...] o papel do aluno, nesse contexto, seria o de “copiar", "repetir", "reter", e "devolver" nas provas do mesmo modo que "recebeu". Um processo com predomínio da memória e da repetição (D’Ambrosio, 1993). Nesse sentido, a licencianda Rubelita explica: “[...] eu acho que Matemática pode ser sinônimo de exercícios 
[...], se você não faz exercícios, você não entende”. Citrino corrobora a opinião da colega: “[...] ou você estuda fazendo exercício ou você não aprende”.

Quando questionados/as sobre as estratégias para vencer as dificuldades com a aprendizagem nas disciplinas de conteúdo específico, a fala preponderante entre os/as estudantes é "ter dedicação e persistência", como diz a estudante Hematita: "Senta e estuda! Eu fui fazer uma prova de Variável Complexa, eu devo ter feito mais de 200 exercícios, pra fazer três (na prova). Sentei e estudei!”.

Subjacente à prática naturalizada de fazer muitos exercícios, não como instrumento para a avaliação da aprendizagem, mas como meio para aprender Matemática, está a ideia de preparação para as provas, como explica Jaspe:

Sempre buscar exercícios para você conseguir fazer na prova, que a maioria das vezes, como aqui a gente tem quatro questões, três provas de 33, se você quer se dar bem no curso, ou seja, formar, você vai decorar os exercícios, que é o que realmente a gente faz, decora os exercícios, pra fazer na prova. Não acho isso certo! [...].

Os/As licenciandos/as utilizaram termos como 'pegar o jeito', 'orienta no estilo do professor', o que acusa a existência de uma visão estática do conteúdo, pois cabe ao/à aluno/a 'provar' que aprendeu. Os depoimentos acima ilustram a crítica que Ubiratan D’Ambrosio faz às provas e aos exames convencionais, quando afirma que é preciso diferenciar educação de treinamento.

Outro obstáculo apontado refere-se à dificuldade para compreender as explicações e demonstrações dos/as docentes durante as aulas, o que pode ser percebido na fala do estudante Euclásio:

É, embora eu tenha muita dificuldade ainda de demonstrar, sabe? De seguir os passos e escrever em Matemática [...]. É, eu fiquei muito perdido sabe? Então, eu não sei se isso é normal, sabe? Eu já perguntei para muita gente aqui, você já ficou perdido em aulas assim? Muitas pessoas já falaram, nó! Não entendi nada do que estava ali no quadro.

Os/As licenciandos/as apontam que seus/as docentes têm um elevado nível intelectual, e este é outro fator dificultador da aprendizagem. Por terem um conhecimento profundo de 
Matemática, os/as professores/as não conseguem explicar de forma que os/as alunos/as compreendam, como menciona a licencianda Rodolita: "Eu acho que eles sabem tanto que, quando eles têm que explicar algo muito fácil, pra eles, na cabeça deles, tá tão bem formado, que eles não conseguem explicar". Um dos diálogos entre licenciandas na roda de conversa mostrou como essa questão afeta o estado emocional e, a nosso ver, por consequência, as aprendizagens:

Rodolita: Eu tenho uma dica para todos os professores, não usem a palavra trivial, porque... (risos)

\section{Sodolita: Nunca é!}

Rodolita: Porque é assim, não vou demonstrar isso, porque isso é trivial. Isso que é trivial, não é trivial para mim, e o professor fala que é trivial e pra mim não é trivial. Eu me sinto numa angústia!

Sodolita: Dá um constrangimento! Eu sinto assim também!

Nesse fragmento de diálogo entre as estudantes, percebe-se dois aspectos a se destacar: a valorização dos/as entendidos/as na matéria apresentada e não explicada pelo/a professor/a (considerada trivial), atribuindo a mensagem de incapazes para aqueles que não compreendem o assunto; mostra-se também como arrogante, pois não possibilita que haja contestação. Consciente ou inconscientemente, em menor ou maior grau, os/as licenciandos/as percebem a Matemática sob a perspectiva formalista clássica em resposta ao que lhes é exigido (e até mesmo imposto) no curso, evidenciando essa concepção quando defendem ou não contestam a repetição exagerada de exercícios, o formato tradicional de aulas - expositivas $-\mathrm{e}$ a preparação para as provas convencionais.

Outra percepção elucidada pelos/as interlocutores/as refere-se à preparação pedagógica dos/as docentes que ministram os conteúdos específicos, questão que discutiremos a seguir.

\section{Da formação pedagógica dos/as docentes formadores/as}


A Lei de Diretrizes e Bases da Educação Nacional - LDB nº 9394/96, Art. 66 preconiza que "a preparação para o exercício do magistério superior far-se-á em nível de pós-graduação, prioritariamente em programas de mestrado e doutorado". Nesse sentido, "a carreira universitária se estabelece na perspectiva de que a formação do professor requer esforços apenas na dimensão científica do docente, materializada pela pós-graduação stricto sensu, nos níveis de mestrado e doutorado" (Cunha, 2005, p. 73).

Por essa ótica, a formação para a docência "explicita um valor revelador de que, para ser professor universitário, o importante é o domínio do conhecimento de sua especialidade e das formas acadêmicas de sua produção" (Cunha, 2005, p. 73). Isso se verifica na Ifes em que realizamos a pesquisa e a maioria dos/as professores/as formadores/as não fez a licenciatura.

A maioria dos/as estudantes investigados/as citou a necessidade de uma mudança na maneira de os/as docentes da licenciatura ensinar a matemática, visando aos modos mais explicativos. Cabe destacar, contudo, que poucos, 21,42\% deles/as, referiram-se explicitamente à falta de preparação pedagógica dos/as docentes que ministram as disciplinas de conteúdo específico como um fator dificultador de suas aprendizagens. Essa situação nos indica a naturalização da prática tradicional como uma marca histórica do ensino de matemática e, até mesmo, uma visão ainda pouco esclarecida, conforme a fala do estudante Euclásio se referindo a um professor: "Porque eu via que ele era preocupado, ele me parecia muito preocupado. Quando eu ia na sala dele, ele sempre tentava me ajudar, mas parece que didática, se didática é um dom, ele não nasceu com esse dom (risos)".

A fala de Euclásio indica, nos termos de Cunha (2005, p. 71), “a concepção de docência como um dom" que, nas palavras da autora, "carrega um desprestígio da sua condição acadêmica, relegando os conhecimentos pedagógicos a um segundo plano e desvalorizando esse campo na formação do docente de todos os níveis, mas, principalmente, o universitário" (Cunha, 2005, p. 7). 


\section{Do rendimento dos/as discentes nas disciplinas de matemática}

A quantidade de alunos/as em sala de aula, nas disciplinas pesquisadas, reduziu-se no decorrer dos semestres, à medida que as provas foram aplicadas e os/as estudantes percebiam que não conseguiriam obter a nota média para aprovação. Assim, ao abandonarem a disciplina, são reprovados/as por frequência, como relata Coralina: "Se você observar bem as turmas aqui, depois da primeira prova diminui o número de alunos, depois da segunda, diminui mais ainda, aí na terceira prova só ficam os 'heróis da resistência"' (risos).

Trata-se de um fenômeno que ocorre em praticamente todas as disciplinas de conteúdo específico, mas, especialmente, em Variável Complexa, no período em que participamos das aulas. De uma das turmas observadas, dos/as 48 alunos/as matriculados/as (10 licenciandos/as), o rendimento foi: aprovação - 19 (39,58 \%); reprovação - $12(25 \%)$, dos quais dois por frequência e 10 por nota; trancamento - 17 (35,42\%). Constatamos que o índice de aprovação é consideravelmente baixo, e o trancamento, parcial elevado. Nas demais disciplinas, os índices também são elevados 5 .

Os fatores mais citados pelos/as licenciandos/as e que contribuem para o baixo rendimento nessas disciplinas são: aulas expositivas com apresentação das demonstrações, provas rigorosas e a relação professor/a-aluno/a. No tocante à correção das provas - erros e acertos -, os relatos indicam que muitos professores são rigorosos na correção, como menciona Esfênio: "Porque, muitas vezes, o professor tira sete pontos, por exemplo, porque o aluno errou um sinal", apontando também o não entendimento na forma de indicação do erro cometido. Tanto opositores quanto defensores da prova convencional consideram a discussão das questões da prova, após a correção, uma tarefa importante, como menciona Citrino:

\footnotetext{
${ }^{5}$ Em relatório da Prograd da IFES, analisando dados dos anos 2010 a 2017, dos/as alunos/as matriculados/as na disciplina 'Fundamentos de geometria plana e desenho geométrico', 50\% foram aprovados/as, 34\% reprovados/as e quase $16 \%$ fizeram trancamento; entre os/as alunos/as na disciplina 'Variável complexa', 53\% foram aprovados/as, 36\% reprovados/as e 16\% trancaram; dos/as que fizeram 'Fundamentos de análise', 69\% foram aprovados/as, $22 \%$ reprovados/as e $9 \%$ trancaram.
} 
É importantíssimo você corrigir para o aluno entender o que ele errou e porque ele errou, e o que que você esperava dele. Inclusive em matérias que são muito mais difíceis, em uma prova de Fundamentos de Análise, de fato muito difícil, tem questões que provavelmente muitos alunos não vão saber resolver.

Contudo, 57,14\% dos/as alunos/as salientam que o principal fator para tal desempenho no curso é o perfil do/a professor/a, em que destacam relação professor/a-aluno/a, especificamente a pouca dialogicidade sobre os conteúdos ensinados. A visão dos/as licenciandos/as sobre os seus professores têm forte interferência nas matrículas semestrais, pois relatam que se matriculam nas disciplinas conforme o/a professor/a que a ministrará, sempre que possível, e, não o/a conhecendo, fazem a tentativa que pode levar à conclusão da disciplina ou ao trancamento. Como relata Esfênio, na matrícula: “[...] uma coisa que nenhum aluno tem coragem de falar, mas é verdade, a gente não escolhe matéria, a gente escolhe professor”.

Outra explicação apresentada pelos/as licenciandos/as, relacionada ao perfil do/a docente formador/a, é a valorização da pesquisa em detrimento do ensino, como diz a licencianda Ágata: “Eles não gostam de dar aula, eles dão aula meio que obrigados [...]. Eles deixam isso bem claro pra gente [...]" e cita a fala de um docente: “- Sim, dar aula para mim é bobagem, trabalho mesmo é pesquisa; a gente trabalha com pesquisa, aula é bobagem”. Esses depoimentos condizem com a afirmação ainda válida de Menezes (1987, p. 120): “A universidade tem aceitado formar professores como uma espécie de tarifa que ela paga para poder fazer ciência em paz”.

Devido a esses fatores é que alguns/as alunos/as dizem que não basta dedicação e esforço para conseguir êxito nas disciplinas de conteúdo específico, como afirma Esmeralda: “Tem professor que você pode estudar o livro inteiro, você pode fazer todos os exercícios, você pode pedir ajuda a Deus que você não consegue fazer a prova dele!’.

Outro aspecto que chama a atenção, segundo alguns/as de nossos/as entrevistados/as, estudantes casados/as e já trabalhadores/as da educação ou fora dela, a condição do/a aluno/a 
não é considerada pelos/as docentes. Citrino afirma e se culpa, referindo-se a professores/as que requerem dedicação aos estudos sem flexibilização:

Reprova porque (...) são os fatores externos, não é ele, a culpa não é dele, o último culpado é ele. O culpado é quem não quer fazer a matéria, é culpado quem desistiu e o culpado é quem faz a própria sociedade entre aspas, porque, porque o cara de fato não tem tempo suficiente para estudar. Então tem a Universidade, mas ele, às vezes, tem que por comida dentro de casa, sabe? Ele tem que, às vezes, trabalhar mesmo, ele quer trabalhar, aí a culpa é dele mesmo, porque ele não dá prioridade à faculdade.

O fato de ser reprovado muitas vezes, trancar ou abandonar uma ou outra disciplina são situações muito presentes e de grande desgaste emocional para os/as estudantes. Gostar de Matemática e ter persistência (força de vontade) são as condições apontadas para se obter aprovação nas disciplinas consideradas difíceis. Nossos/as pesquisados/as, licenciandos/as, já na segunda fase do curso, passaram por forte seleção vivenciada na primeira fase, constituindose em um grupo bem menor do que o do ingresso no vestibular. Muitos/as mencionam que esse processo é doloroso, afeta a autoestima e provoca adoecimento, como aponta Esmeralda:

Eu tive depressão no primeiro ano que eu entrei aqui. Uma depressão muito forte, assim, de quase que eu, assim, eu não tentei o suicídio, porque eu não tenho, eu acho que eu não seria capaz disso, mas era como se... você se sente assim, inferior, você se sente sozinha... e você parece que você tá afogando no mar, e não tem ninguém para te ajudar. Assim, eu só conseguir mudar mesmo, no segundo ano. Então eu passei um ano inteiro, perdi dois semestres aqui.

De acordo com o Regimento Geral da Instituição, os/as estudantes precisam ter um Rendimento Semestral Geral (RSG) médio para se manterem no curso. Nas disciplinas de conteúdo específico, eles/as utilizam diversas estratégias para manter essa média e não jubilar, como o trancamento parcial. O esforço para obter nota para aprovação, destacar-se e corresponder às expectativas dos/as docentes geram danos para a saúde física e emocional dos/as estudantes, conforme comentários de Ametista, a seguir:

Aí, no início de 2015, eu fiz matrícula e vim para ele (professor) chorando, desesperada, chorava horrores, falei com ele assim que eu não queria, que eu ia trancar e abandonar e não ia voltar [...]. Eu estava tão nervosa que eu cheguei a ter quase um princípio de infarto, sabe? Eu fui parar no hospital por crise nervosa. Então deu uma anemia, é... 
desencadeou mil coisas, eu engordei horrores nessa época, eu não tinha esse corpo, eu era muito mais magra. Aí tá, aí tranquei o curso [...].

Assim como Esmeralda e Ametista, outros/as estudantes mencionaram que se sentem inferiorizados/as, incapazes, porque, apesar do esforço e dedicação, não conseguem evitar a reprovação e o abandono, mas se dizem resistentes por já estarem na segunda etapa do curso. Não observamos a existência de tempos e espaços na Ifes para que os/as estudantes pudessem tratar do tema avaliação durante o curso.

Entendemos que esse conjunto de fatores explicitados pelos/as licenciandos/as que geram doenças físicas e psicológicas e, consequentemente, afetam suas aprendizagens, podem ser explicados por meio do conceito 'violência simbólica', em particular, na noção de 'arbitrário cultural', ou seja, imposição explícita de uma cultura dominante, no caso, da concepção formalista clássica de Matemática. Para Bourdieu e Passeron (1982, p. 20), "toda ação pedagógica (AP) é objetivamente uma violência simbólica, enquanto imposição, por um poder arbitrário, de um arbitrário cultural".

Seria um arbitrário cultural a imposição dos valores e significados próprios da concepção formalista clássica de Matemática, predominante nas práticas relatadas pelos/as licenciandos/as? De acordo com Nogueira e Nogueira (2005, p. 36), a imposição de valores e significados em uma ação pedagógica "seriam vividos pelos indivíduos como os únicos possíveis ou, pelos menos, como os únicos legítimos”. Nesses termos, a forma de ver e conceber a Matemática na perspectiva formalista clássica seria, assim, socialmente reconhecida como a única válida universalmente, supostamente neutra e, portanto, imposta a todos/as os/as estudantes - a violência simbólica, conforme Bourdieu e Passeron (1982). Nogueira e Nogueira (2015) explicam esse conceito em Bourdieu:

A autoridade alcançada por uma ação pedagógica, ou seja, a legitimidade conferida a essa ação e aos conteúdos que ela distribui seria proporcional à sua capacidade de se apresentar como não arbitrária e não vinculada a nenhuma classe social. Esse processo de imposição dissimulada de um arbitrário cultural como cultura universal é denominado, pelo autor, de "violência simbólica" (Nogueira \& Nogueira, 2015, p. 37). 
Bourdieu e Passeron (1982) esclarecem que as bases da violência simbólica se encontram nas relações de força que são estabelecidas na ação pedagógica (AP). Para os autores,

As relações de força determinam o modo de imposição característico de uma AP, como sistema dos meios necessários para a imposição de um arbitrário cultural e para a dissimulação do duplo arbitrário dessa imposição, isto é, como combinação histórica dos instrumentos de violência simbólica e dos instrumentos de dissimulação (isto é, de legitimação) dessa violência (Bourdieu \& Passeron, 1982, p. 29).

Referenciando-nos nesses autores, perguntamos: qual a relação do poder interno do campo da Matemática e a acumulação de capitais com a avaliação da aprendizagem? Os detentores do poder, no campo da Matemática, utilizam a avaliação para classificar, principalmente por meio da prova convencional e, assim, selecionar os/as estudantes autodidatas, 'brilhantes', que, não raro, são os/as herdeiros/as da cultura legitimada, ou seja, da Matemática formal, clássica. Essa classificação e seleção seria, portanto, realizada por meio de forte violência simbólica, gerando elevados índices de reprovação e abandono, assim como entende como notáveis aqueles/as que conseguem concluir o curso.

O/as licenciando(a)s que concluem o curso se mostram vitoriosos, de fato alcançaram seu final passando por várias barreiras. Será que essa sensação virá a refletir em suas ações docentes no futuro?

Dessa forma, propaga-se a ideia de que a Matemática é uma disciplina difícil, exige muito esforço e dedicação, além de habilidades natas, inteligência, por conseguinte, é acessível para poucos. No entanto, Bourdieu (1989, p. 18) afirma que "nada é mais universal e universalizável do que as dificuldades. Cada um achará uma certa consolação no facto de descobrir que grande número das dificuldades imputadas em especial à sua falta de habilidade ou à sua incompetência, são universalmente partilhadas" (Bourdieu, 1989, p. 18).

\section{Concluindo}


Nas disciplinas de conteúdo específico matemático na Licenciatura em Matemática, nesta pesquisa, predomina a prática de provas rigorosas e consideradas difíceis, conforme relatos dos/as estudantes da investigação. O processo da avaliação é muito criticado pelos/as licenciandos/as e gera medo, insegurança e indignação. O curso convive com altos índices de reprovação e evasão e coloca a maior parte dos/as alunos/as em uma atitude de resignação, devido à dificuldade para obtenção de média para aprovação e por não perceberem meios para promover mudanças. Mesmo aqueles/as que questionam as provas tradicionais não demonstraram ter conhecimento da avaliação com função formativa, investigativa, para contrapor à concepção predominante.

É importante sublinhar que, mesmo submetidos/as e críticos/as ao sistema de avaliação do curso aqui tratado, todos/as os/as interlocutores/as advogaram a favor da prova convencional como o instrumento mais adequado para avaliar a aprendizagem. Alguns/as defendem enfaticamente a aplicação da prova como instrumento único e fidedigno de verificação da aprendizagem e mencionam que flexibilizar a avaliação por meio de outros instrumentos facilita a aprovação, rebaixa o nível de exigência e, portanto, a qualidade do curso.

Outros/as defendem a flexibilização e a diversificação de instrumentos avaliativos, como a inclusão de trabalhos - entendidos como resolução de listas de exercícios, seminários e outros -, e incluem a aplicação de provas. Ainda que manifestem a necessidade de certa flexibilidade nas correções das provas, a prova é reconhecida e validada. Desse modo, por não terem mostrado uma visão explícita do papel da avaliação com função formativa, as sugestões dos/as licenciandos/as de adoção de outras formas complementares de avaliação indicam a busca por uma facilitação nos resultados, o que não é aceitável pela maior parte deles/as mesmos/as. Expressa-se, assim, a avaliação do curso analisado, como um processo de conflitos e angústias para os/as licenciandos/as. 
Aqueles/as licenciandos/as que têm uma compreensão de avaliação mais próxima da perspectiva formativa defendem a flexibilidade e a diversificação dos instrumentos, porém seus argumentos não ecoam nem mesmo entre os pares. Há um silenciamento entre nossos/as interlocutores/as em relação à concepção de avaliação como investigação - formativa, integrada à prática pedagógica - das dificuldades e dos avanços no decorrer dos processos de ensinar e aprender.

Consideramos que as questões relativas à avaliação da aprendizagem são um grande desafio no processo de formação dos/as futuros/as professores/as de Matemática porque, como afirma Luckesi (2018), ao trabalhar "para que todos os estudantes atinjam a aprendizagem de modo satisfatório, estamos decidindo abrir mão da seletividade e da exclusão, fator que conduz também a abrir mão de contribuir para a seletividade social própria do modelo de organização social do capital [...]” (Luckesi,, 2018, p. 89). Fato que evidencia a necessidade de inserção de estudos teórico-práticos mais sistematizados sobre avaliação da aprendizagem no curso de Licenciatura em Matemática.

Percebe-se, assim, a violência simbólica nos termos de Bourdieu (2016, p. 248), ou seja, as "práticas de exclusão brandas, ou melhor, insensíveis, no duplo sentido de contínuas, graduais e imperceptíveis, desapercebidas, tanto para aqueles que as exercem como para aqueles que são suas vítimas". Elevados índices de reprovação e evasão constituem um fenômeno que tem se perpetuado de geração em geração, acarretando muitos prejuízos econômicos, sociais e políticos, especialmente para a formação dos/as futuros/as professores/as de Matemática para a educação básica.

\section{Referências}

Bardin, L. (2016). Análise de Conteúdo. Edições 70.

Bourdieu, P. (1989). O poder Simbólico. Bertrand Brasil.

Bourdieu, P. (2004). Os usos sociais da ciência: por uma sociologia clínica do campo científico. Ed. da Unesp. 
Bourdieu, P. (2015). Economia das trocas simbólicas. Perspectiva.

Bourdieu, P. (2017). A distinção: crítica social do julgamento. Zouk.

Bourdieu, P \& PASSERON, JC. (1982). A reprodução: elementos para uma teoria do sistema de ensino. Francisco Alves.

Bourdieu, P. \& Passeron, JC. (2015). Os herdeiros: os estudantes e a cultura. Ed. da UFSC.

Buriasco, R. L. C. \& Soares, M. T. C. (2008). Avaliação de sistemas escolares: da classificação dos alunos à perspectiva de análise de sua produção matemática. In: W. R. Valente (org.). Avaliação em Matemática: história e perspectivas atuais. Papirus, (pp.101-142).

Cunha, M. I. (2005). Avaliação e poder na docência universitária: campos legitimados e saberes silenciados. In: M. I. Cunha (org.). Formatos avaliativos e concepção de docência. Autores Associados, (pp. 93-116).

D’Ambrosio, B. (1993). Formação de professores de Matemática para o século XXI: o grande desafio. Pro-Posições, v. 4, n. 1, (pp. 35-41).

D’Ambrosio, B. (1989) Como ensinar matemática hoje? Temas e Debates. SBEM. n. 2.

D’Ambrosio, U. (2007). Educação Matemática: da teoria à prática. Papirus.

Fiorentini, D. (2005). A formação matemática e didático-pedagógica nas disciplinas de Licenciatura em Matemática. Revista de Educação PUC-Campinas, n. 18, (pp. 107115). http://periodicos.puc-campinas.edu.br/seer/index.php/reveducacao/issue/view/43

Fischer, M. C. B. (2008). Os formadores de professores de Matemática e suas práticas avaliativas. In: S. R. Valente. (org.). Avaliação em Matemática: história e perspectivas atuais. Papirus, (pp. 75-100).

Freire, P. (2005). Educação como prática de liberdade. Paz e terra.

Gatti, B. A. \& Barreto, E. S.S. (Coord.). (2009). Professores do Brasil: impasses e desafios. UNESCO. https://www.fcc.org.br/fcc/wp-content/uploads/2019/04/Professores-doBrasil-impasses-e-desafios.pdf

Inep. Instituto Nacional de Estudos e Pesquisas Educacionais. (2020). Indicadores educacionais. Brasília, DF: INEP, [s. d.]. http://portal.inep.gov.br/guest/indicadoreseducacionais.

Jourdain, A. \& Naulin, S. (2017). A teoria de Pierre Bourdieu e seus usos sociológicos. Vozes.

Lei $n^{\circ}$ 9.394, de 20 de dezembro de 1996. (1996) Estabelece as diretrizes e bases da educação nacional. Brasília. http://www.planalto.gov.br/ccivil_03/leis/L9394.htm.

Luckesi, C. C. (2018). Avaliação em educação: questões epistemológicas e práticas. Cortez.

Ludcke, M. \& ANDRÉ, M. E. D. A. (1986). Pesquisa em Educação: abordagens qualitativas. EPU. https://ojs.ufgd.edu.br/index.php/horizontes/article/view/3759

Menezes, L. C. (1987). Formar professores: tarefa da universidade. In: D. B. Catani et al. (org.) Universidade, escola e formação de professores. Brasiliense, (pp. 115-125).

Moreira, P. C.; Ferreira, E.B.; Jordane, A.; Nóbriga. J.C.C.; Fischer, M.C.B.; Silveira, E. \& Borba, M.C. (2012) Quem quer ser professor de matemática? Zetetiké, v. 20, n. 1[37], jan./jun. /https://periodicos.sbu.unicamp.br/ojs/index.php/zetetike/issue/view/1221 
Nogueira, C. M. M. \& Nogueira, M. A. (2005). Um arbitrário cultural dominante. Revista Educação. Especial Biblioteca do Professor n. 5. (Bourdieu pensa a educação). Editora Segmento.

Nogueira, C. M. M. \& Nogueira, M. A. (2016). Bourdieu e a educação. Autêntica.

Polettini, A. F. F. (1996). História de vida relacionada ao ensino da Matemática no estudo dos processos de mudança e desenvolvimento de professores. Zetetiké, v. 4, n. 5, (pp. 2948). https://periodicos.sbu.unicamp.br/ojs/index.php/zetetike/issue/view/1238

Silva, N. M. (2014). Avaliação: ponte, escada ou obstáculo? Saberes sobre as práticas avaliativas em Cursos de Licenciatura em Matemática. 2014. Dissertação (Mestrado) - Universidade Federal de Ouro Preto.

Soares, M. B. (1989). Avaliação Educacional e clientela escolar. In: M. H. S Patto (org.). Introdução à Psicologia Escolar, (pp. 47-53). 